\title{
Influence of V Precipitates on Acicular Ferrite Transformation Part 1: The Role of Nitrogen
}

\author{
Carlos GARCIA-MATEO, Carlos CAPDEVILA, Francisca G. CABALLERO and Carlos Garcia de ANDRÉS \\ MATERALIA Research Group, Department of Physical Metallurgy, Centro Nacional de Investigaciones Metalúrgicas (CENIM), \\ Consejo Superior de Investigaciones Científicas (CSIC), Avda. Gregorio del Amo, 8. E-28040 Madrid, Spain. \\ E-mail:cgm@cenim.csic.es
}

(Received on February 25, 2008; accepted on June 3, 2008)

\begin{abstract}
This paper (part 1 of a two part study) deals with the influence of $N$ in its combination with $V$, as $V(C, N)$ precipitates, on the decomposition of austenite into acicular ferrite. Likewise, the intragranular nucleation potency of $\mathrm{V}(\mathrm{C}, \mathrm{N})$ precipitates is analyzed through the continuous cooling transformation diagrams (CCT) of two $\mathrm{C}-\mathrm{Mn}-\mathrm{V}$ steels with different contents of $\mathrm{N}$ under two different austenitising temperatures, i.e. different austenite grain sizes. The results clearly show that for austenite to decompose into acicular ferrite is necessary, first to have a representative fraction of $\mathrm{V}(\mathrm{C}, \mathrm{N})$ precipitates within austenite, and second to decorate the austenite grain boundaries with proeutectoid ferrite so bainite can not form. Part 2 of the study concerns with the influence that those precipitates have on the kinetics of acicular ferrite formation during austenite isothermal decomposition.
\end{abstract}

KEY WORDS: acicular ferrite; bainite; V(C, N); continuous cooling transformation diagrams.

\section{Introduction}

Acicular microstructures obtained by transformation of austenite into bainitic ferrite and/or acicular ferrite, are gaining an increasing interest on behalf of steel industry. On a permanent quest for better properties and more reliable products, these types of microstructures appear as a very promising solution. The peculiarities of both transformations, between diffusional (proeutectoid ferrite and pearlite) and displacive (martensite) ones, lead to chaotic and very fine microstructures as a natural consequence of their atomic mechanisms.

There are evidences proving that in most of the cases, acicular ferrite (AF) is effectively intragranular bainite, nucleating in certain inclusions and/or precipitates. As an example, acicular ferrite formation occurs below the bainite start temperature $\mathrm{B}_{\mathrm{S}}$ and above the martensite start temperature $\mathrm{M}_{\mathrm{S}}{ }^{1)}$ and it suffers of the so called incomplete reaction phenomenon. ${ }^{2)}$ The growth of AF is accompanied by a shape deformation which is characterized as an invariant plane strain with a large shear component, leading to a stored energy of about $400 \mathrm{~J} \mathrm{~mol}^{-1}$, similar to that of bainite. ${ }^{3)}$ Both, bainite and AF, keep a well-defined crystallographic orientation relationship with the parent austenite $(\gamma)$ from which they grow, and indeed growth is limited in both cases to the austenite grain size because the coordinated motion of atoms cannot be sustained across an arbitrary grain boundary. ${ }^{2,3)}$ There is no partitioning of substitutional elements during growth, ${ }^{2,4)}$ so both bainite and AF can be no-random oriented by applying elastic stress, or suffer of mechanical stabilisation when enough plastic de- formation is applied. ${ }^{3,5,6)}$

Four plausible mechanisms have been proposed in order to explain nucleation of $\mathrm{AF}$ at non-metallic inclusions and precipitates, ${ }^{7-14)}$ and they are: (1) the inclusions/precipitates act as inert surfaces leading to a reduction of the activation energy and ferrite $(\alpha)$ nucleation is promoted, (2) small lattice mismatch between the inclusions or precipitates and the matrix can also reduce the activation energy for nucleation, (3) inclusions and precipitates may deplete elements such as $\mathrm{C}$, Mn and Si from $\gamma$, which may lead to local increase in the driving force for the nucleation of $\alpha$ from $\gamma$ in the inclusion/precipitate surface, (4) volume strain due to differences in thermal expansion coefficients of $\gamma$ and inclusion/precipitate, develops thermal strains near the interface, therefore reduces the activation energy for the formation of a $\alpha$ nucleus. So far none of the above mechanisms have been proved to be, individually, the main mechanism for nucleation, but rather the combined effect of several of them.

Once that some general and common aspects for both bainite and AF transformations have been described, it is necessary to highlight their main differences. Thus, while bainite nucleates at the austenite grain boundaries (AGB), that is intergranularly, AF does it on inclusions or precipitates, intragranularly. Thus AF exhibits a more chaotic arrangement of ferrite plates than bainite, which is considered to be the main reason to the improved toughness behaviour when compared to bainite.

Essentially, and based on the above mentioned information, one can conclude that the transformation mechanism of $\mathrm{AF}$ and bainite are similar, except for the requirement of 
potent inclusions/precipitates within austenite for AF formation.

Given that bainite and AF might be competitive microstructures in the temperature range between $B_{S}$ and $M_{S}$, the different ways to switch between one or the other are described as follows. To promote AF formation the first method relies on reducing the AGB area per unit volume, that is increasing the austenite grain size. Since bainite nucleates intergranularly, bigger grain sizes will slow down the kinetics and favour intragranular nucleation, also by increasing the grain size the probability of trapping more inclusions/precipitates within austenite is also intensified. In the second method the aim is to dishabilitate the bainite nucleation sites, i.e. AGB. This is achieved by decorating the grain boundary with fine proeutectoid ferrite. ${ }^{15)}$ It has also been postulated that $\mathrm{B}$ or $\mathrm{Mn}$ segregation to the $\gamma-\gamma$ grain boundaries reduces the driving force for bainite nucleation at the interface. ${ }^{15)}$ Finally, the last and more obvious method is related to the presence of potent inclusions or precipitates within the $\gamma$ grain, if there are none, acicular ferrite formation will never occur.

It has been shown that $\mathrm{V}(\mathrm{C}, \mathrm{N})$ precipitates associated with $\mathrm{MnS},{ }^{16)}$ or introduced in the steel as sintered polycrystal ceramics, ${ }^{17)}$ or obtained during austenite deformation ${ }^{18)}$ are responsible of intragranular ferrite nucleation. In this work the influence of $\mathrm{N}$ on the anisothermal decomposition of austenite in two $\mathrm{V}$ alloyed steels is analyzed. The aim is to elucidate the potency of $\mathrm{V}(\mathrm{C}, \mathrm{N})$ precipitates for the nucleation of AF. To facilitate this, continuous cooling transformation (CCT) diagrams under different austenitising conditions of two experimental steels containing $\mathrm{V}$ in the same quantity but with and nearly without $\mathrm{N}$ have been studied.

\section{Material and Experimental Techniques}

The chemical composition of the two laboratory grades used in this work are listed in Table 1. Both are low $\mathrm{C}-\mathrm{Mn}-\mathrm{V}$ steels with traces of other elements, the $\mathrm{N}$ content was intentionally different, thus $4 \mathrm{~B}$ steel has a low $\mathrm{N}$ level compare with $5 \mathrm{~B}$, one order of magnitude less. Materials were $100 \mathrm{~kg}$ ingots, hot rolled from a thickness of $120 \mathrm{~mm}$ down to $15 \mathrm{~mm}$ and air-cooled from a finish rolling temper-

Table 1. Chemical compositions of the experimental grades, all in $w t \%$.

\begin{tabular}{c|c|c|c|c|c|c|c}
\hline Grade & $\mathrm{C}$ & $\mathrm{Mn}$ & $\mathrm{V}$ & $\mathrm{N}$ & $\mathrm{Al}$ & $\mathrm{Si}$ & $\mathrm{S}$ \\
\hline 4B & 0.08 & 1.46 & 0.25 & 0.0016 & 0.020 & 0.004 & 0.001 \\
5B & 0.08 & 1.46 & 0.25 & 0.0180 & 0.016 & 0.007 & 0.001 \\
\hline
\end{tabular}

ature of about $1050^{\circ} \mathrm{C}$. The length and width of the plates were $1050 \mathrm{~mm}$ and $160 \mathrm{~mm}$, respectively. After rolling, the plates were cut in two pieces of $15 \times 150 \times 400 \mathrm{~mm}$, being those the as-received conditions.

An Adamel Lhomargy DT1000 high resolution dilatometer has been used to determine the CCT diagrams of the steels. A detailed description of the dilatometer and its excellent efficiency for this type of work can be found in Ref. 19).

Cylindrical dilatometric specimens of $2 \mathrm{~mm}$ diameter and $12 \mathrm{~mm}$ length were austenitised and then continuous cooled at different rates down to room temperature. Specimens were polished and etched in the usual way for further metallographic examination by means of optical microscopy. Then, the criteria followed to discern between AF or bainite was the almost parallel or chaotic arrangement of the ferrite plates respectively. Selected samples were prepared with colloidal silica for EDX analysis in a field emission gun scanning electron microscopy. The previous austenite grain size (PAGS) was revealed by means of the thermal etching technique. ${ }^{20)}$

A set of theoretical calculations concerning temperature evolution of different phases present, as well as their compositions were performed with the help of a commercial package for thermodynamic calculations in equilibrium in combination with the SGSOL-SGTE Solution database 3.0. ${ }^{21)}$

\section{Results and Discussion}

Figures 1 and 2 show calculated equilibrium fraction of $\mathrm{V}(\mathrm{C}, \mathrm{N})$ precipitates and its chemical composition as a function of the temperature. Results in Fig. 2 represents how the actual chemical composition of $\mathrm{V}(\mathrm{C}, \mathrm{N})$ precipitates evolve as temperature changes, the straight lines rep-

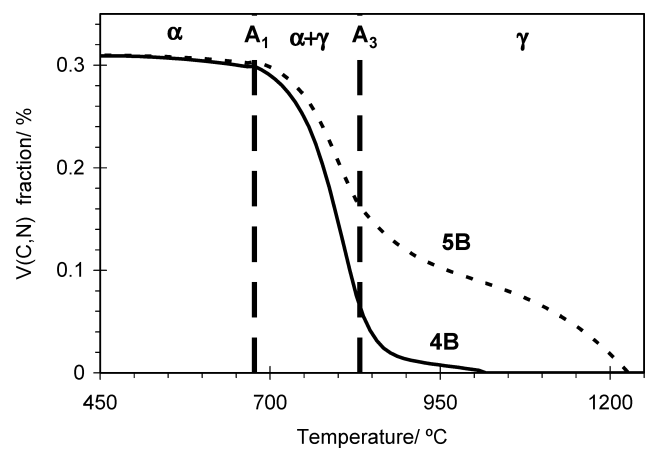

Fig. 1. Calculated equilibrium $V(C, N)$ fraction and $A_{1}$ and $A_{3}$ temperatures.
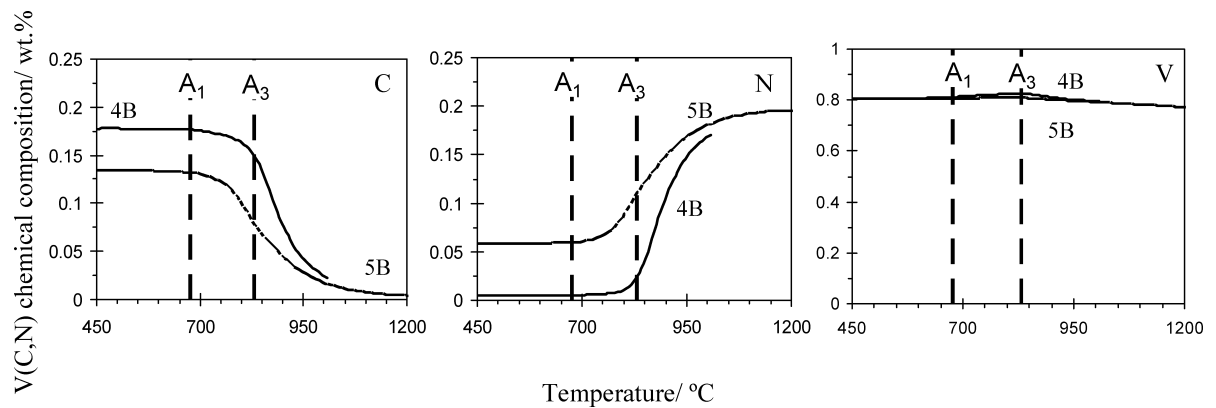

Fig. 2. Calculated equilibrium chemical composition of $\mathrm{V}(\mathrm{C}, \mathrm{N})$ and $\mathrm{A}_{1}$ and $\mathrm{A}_{3}$ temperatures. 
resent the boundary temperatures for the $\gamma, \alpha+\gamma$ and $\alpha$ fields, i.e. $\mathrm{A}_{3}$ and $\mathrm{A}_{1}$ temperatures respectively. The results of the present calculations confirm that $\mathrm{V}(\mathrm{C}, \mathrm{N})$ precipitates are thermodynamically stable over a range of temperatures for both steels. It is not strange that at low temperature, ferrite field, the expected fraction of $\mathrm{V}(\mathrm{C}, \mathrm{N})$ is the same for both steels, Fig. 1. The main difference resides in how this $\mathrm{V}$ is combined. Thus, in $5 \mathrm{~B}$ steel at the $\mathrm{A}_{3}$ temperature $\sim 50 \%$ of the total precipitation has already taken place, and composition calculations in Fig. 2 reveal that at this point most of the $\mathrm{N}$ has been consumed in forming $\mathrm{V}(\mathrm{C}, \mathrm{N})$ precipitates. It is also shown the gradual evolution from almost pure nitride to $\mathrm{C}$ rich carbonitrides as the temperature is decreased. On the other hand in the case of $4 \mathrm{~B}$ steel, low $\mathrm{N}$ content, precipitates in the $\gamma$ field start appearing at lower temperatures than $5 \mathrm{~B}$ steel, and represent only $\sim 14 \%$ of the total, containing less $\mathrm{N}$ and more $\mathrm{C}$ than those in $5 \mathrm{~B}$. As in the latter most of the $\mathrm{N}$ is consumed in the $\gamma$ field. Summarising, we are dealing with two very distinctive situations at $\mathrm{A}_{3}$ temperature, on one hand $5 \mathrm{~B}$ steel with a representative fraction of potent nucleation sites, almost pure nitrides, within $\gamma$ for AF formation, while on the other hand, 4B has a more limited amount of precipitates and not as rich in $\mathrm{N}$ as those in $5 \mathrm{~B}$.

Since PAGS is a key parameter in the anisothermal decomposition of austenite it is necessary to achieve similar values in both steels. Figure 3 gathers the PAGS measured for both steels under different austenitising temperatures, $T_{\gamma}$. For the purpose of this work a small and intermediatehigh PAGS were selected, i.e. 20 and $60 \mu \mathrm{m}$ corresponding to $T_{\gamma} 975$ and $1125^{\circ} \mathrm{C}$ for $120 \mathrm{~s}$ for both steels respectively, meaning a situation where AF formation is not stimulated and another one where indeed it is. It can be argued that $1200^{\circ} \mathrm{C}$ would have been a more suitable austenitising temperature in order to obtain a big PAGS, but $170 \mu \mathrm{m}$ is far from that obtained in the industrial product for which these steels are aimed, being $60 \mu \mathrm{m}$ more realistic approach. It is also necessary to point out that the very similar PAGS reported in Fig. 3, regardless the $T_{\gamma}$ temperature, clearly indicates that the present precipitates during austenitisation are unable to exert pinning effect during grain growth, most probably because during heating and following austenitisation precipitates coarsen either due to its ripening, precipitation over already existing ones or growth, therefore losing its ability to pin the AGB. ${ }^{22-24)}$

In order to analyse the effect of $\mathrm{N}$ on decomposition of

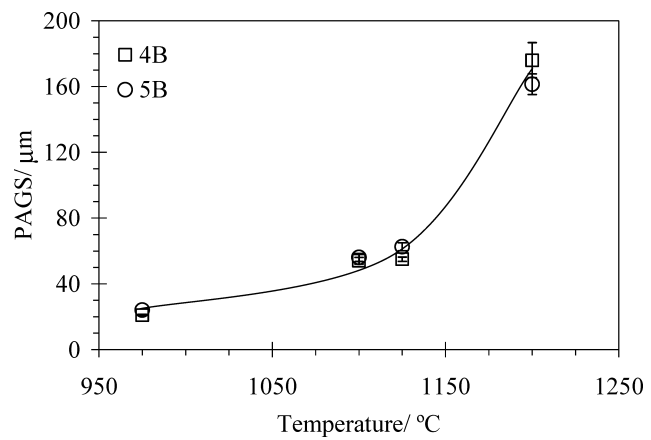

Fig. 3. Evolution of previous austenite grain size (PAGS) after $120 \mathrm{~s}$ at different austenitising temperatures $\left(T_{\gamma}\right)$ in both studied steels. austenite in AF, during continuous cooling, the CCT diagrams were determined for the selected $T_{\gamma}$ temperatures. Different cooling rates from $T_{\gamma}$ to room temperature were applied, i.e. $0.5-1-2-4-6-10-25-50-100^{\circ} \mathrm{C} \mathrm{s}^{-1}$. The corresponding CCT diagrams are in Figs. 4 and 5, where the re-
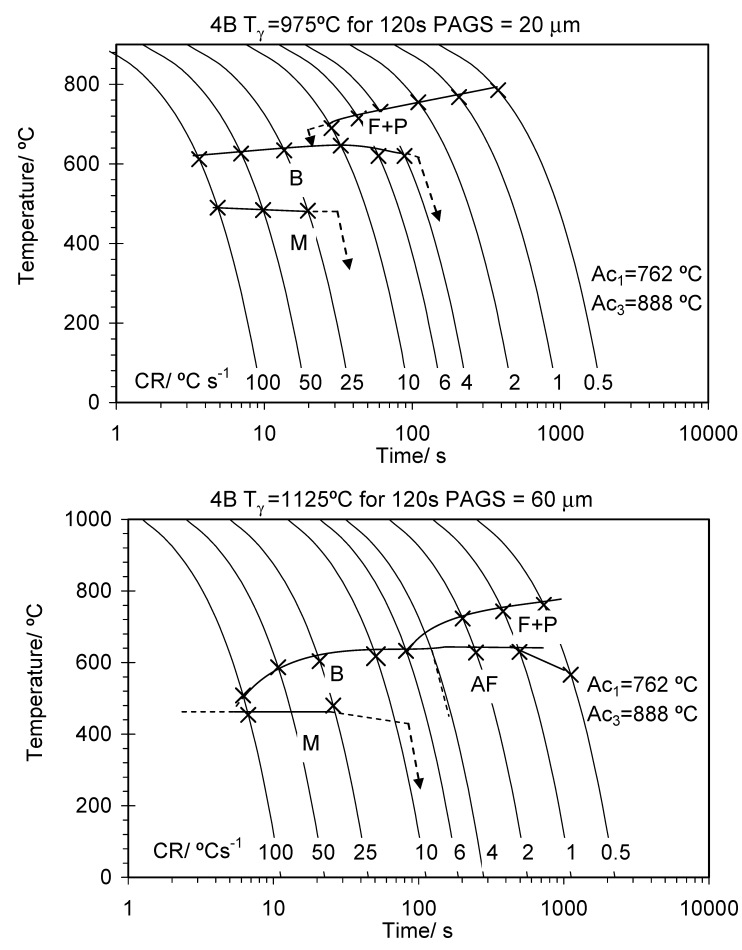

Fig. 4. CCT diagrams for $4 \mathrm{~B}$ steel. $\mathrm{Ac}_{1}$ and $\mathrm{Ac}_{3}$ are those experimentally obtained, $T_{\gamma}$ is the austenitising temperature and PAGS the prior austenite grain size. P stands for pearlite, $\mathrm{F}$ for proeutectoid ferrite, $\mathrm{B}$ for bainite, AF for acicular ferrite and $\mathrm{M}$ for martensite.


Fig. 5. CCT diagrams for $5 \mathrm{~B}$ steel. $\mathrm{Ac}_{1}$ and $\mathrm{Ac}_{3}$ are those experimentally obtained, $T_{\gamma}$ is the austenitising temperature and PAGS the prior austenite grain size. P stands for pearlite, $\mathrm{F}$ for proeutectoid ferrite, $\mathrm{B}$ for bainite, AF for acicular ferrite and $\mathrm{M}$ for martensite. 
ported $\mathrm{Ac}_{1}$ and $\mathrm{Ac}_{3}$ are those experimentally obtained from the heating dilatometric curves. During cooling from $T_{\gamma}$ it is also expected that some precipitation in austenite occurs. At fast cooling rates depresses the transformation temperature and refines precipitate sizes. ${ }^{25,26)}$ So it is anticipated that the higher the cooling rates are the lower the fraction of $\mathrm{V}(\mathrm{C}, \mathrm{N})$ precipittaes in austenite although finer, just the opposite effect when cooling rate is decreased, higher fraction of coarser precipitates. Also, for the same cooling rate, the time necessary to achieve a given temperature increases as the austenitisation temperature does, meaning that there is more time for precipitation when $T_{\gamma}=1125^{\circ} \mathrm{C}$ than when $T_{\gamma}=975^{\circ} \mathrm{C}$. Invariably the equilibrium sequence previously described, from almost pure nitride to $\mathrm{C}$ rich carbonitride as temperature decreases is still applicable, because the much higher driving force for precipitation of nitrides compare to carbides at all temperatures. ${ }^{27)}$

At first sight the 4B and 5B steel CCT diagrams exhibit a very clear difference, i.e. formation of proeutectoid ferrite takes place within a wider range of cooling rates in $5 \mathrm{~B}$ when compared with $4 \mathrm{~B}$ at both austenitising temperatures. This could be explained in terms of the higher presence of $\mathrm{V}$ precipitates that may act as nucleation for sites idiomorphic ferrite, i.e. intragranurlaly nucleated. The consequent boost in proeutectoid ferrite nucleation events leads also to a more refined ferritic grain, compare for example Fig. 6(a) and Fig. 7(a). It is also noticeable that, as expected, reduction of the AGS also enhances proeutectoid ferrite and
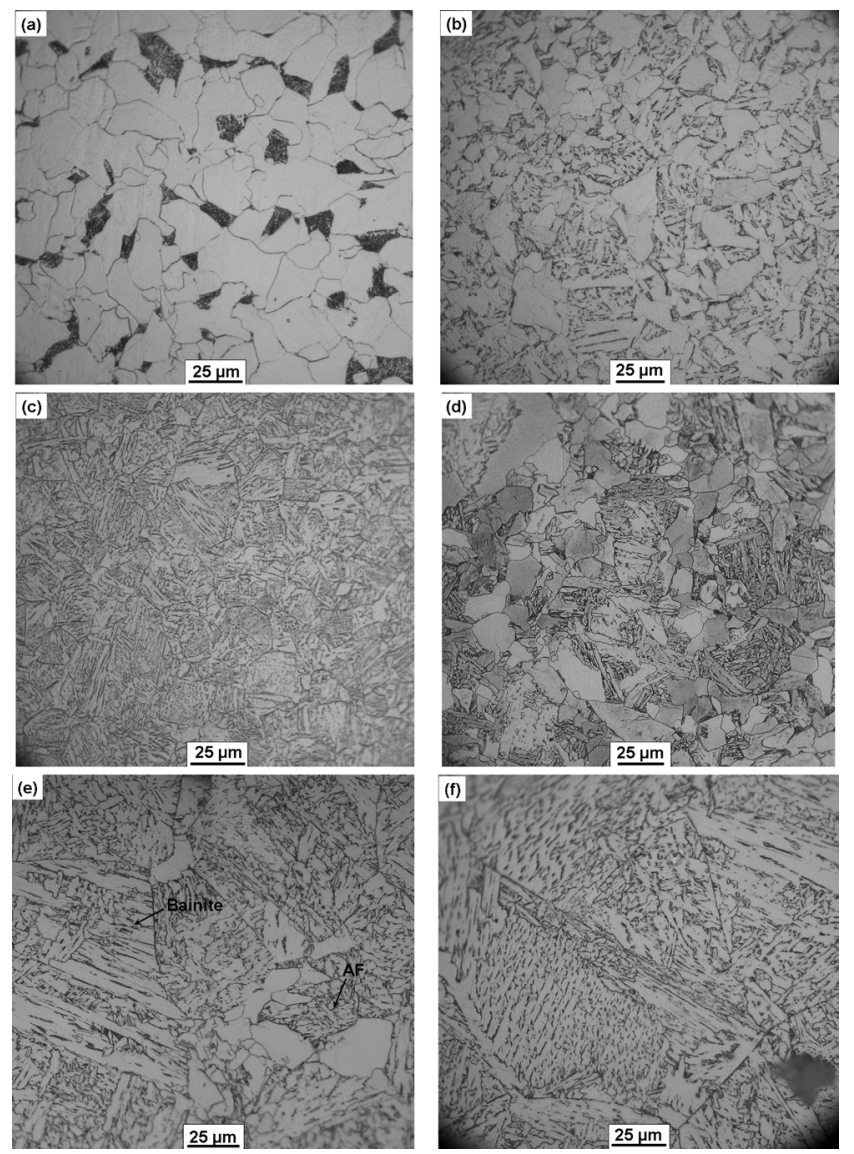

Fig. 6. Microstructures obtained in $4 \mathrm{~B}$ after; austenitised at $T_{\gamma}=975^{\circ} \mathrm{C}$ and cooling at (a) $1^{\circ} \mathrm{C} / \mathrm{s}$, (b) $6^{\circ} \mathrm{C} / \mathrm{s}$ and (c) $25^{\circ} \mathrm{C} / \mathrm{s}$, austenitised at $T_{\gamma}=1125^{\circ} \mathrm{C}$ and cooling at (d) $1{ }^{\circ} \mathrm{C} / \mathrm{s}$, (e) $4^{\circ} \mathrm{C} / \mathrm{s}$, and (f) $10^{\circ} \mathrm{C} / \mathrm{s}$. pearlite transformation, being this the reason for having in both steels a wider range of cooling rates where these two phases are observed when $T_{\gamma}$ is reduced from 1125 to $975^{\circ} \mathrm{C}$. On the other hand it was metallographically assessed that ferrite fraction decreased as the cooling rate increased in all the cases. It will become clear in the following paragraphs that proeutectoid ferrite is playing an important role in the AF formation as well.

As previously outlined, given that bainite nucleates at austenite grain boundaries, a reduction of its size will promote bainite instead of AF. But if those grain boundaries are decorated with proeutectoid ferrite then it can be disable for bainite nucleation, and AF will form as long as effective precipitates for AF nucleation are present, and this is essentially the situation taking place in both steels at $T_{\gamma}=975^{\circ} \mathrm{C}$. At $T_{\gamma}=975^{\circ} \mathrm{C}$ and low cooling rates both $4 \mathrm{~B}$ and $5 \mathrm{~B}$ steel, exhibit a microstructure mainly composed by ferrite and some pearlite that tends to disappear as the cooling rate is increased and more AF or bainite starts to transform. As it was described, when cooling from $975^{\circ} \mathrm{C}$ in $4 \mathrm{~B}$ steel a scarce fraction of precipitates is expected, so the lacking of potent nucleation sites for AF together with the fact that measured PAGS is small, $\sim 20 \mu \mathrm{m}$, leads to bainite formation even when proeutectoid ferrite may have formed at grain boundaries, e.g. $10-4^{\circ} \mathrm{C} / \mathrm{s}$ cooling rates in Fig. 4 and Fig. 6(b). In Fig. 6(c) is shown an example of the bainitic microstructure obtained after cooling at $25^{\circ} \mathrm{C} / \mathrm{s}$, characterised by the parallel arrangements of ferrite plates.


Fig. 7. Microstructures obtained in 5B after; austenitised at $T_{\gamma}=975^{\circ} \mathrm{C}$ and cooling at (a) $4^{\circ} \mathrm{C} / \mathrm{s}$, (b) $25^{\circ} \mathrm{C} / \mathrm{s}$ and (c) $50^{\circ} \mathrm{C} / \mathrm{s}$, austenitised at $T_{\gamma}=1125^{\circ} \mathrm{C}$ and cooling at (d) $6^{\circ} \mathrm{C} / \mathrm{s}$, (e) $10^{\circ} \mathrm{C} / \mathrm{s}$, and (f) $100^{\circ} \mathrm{C} / \mathrm{s}$. 

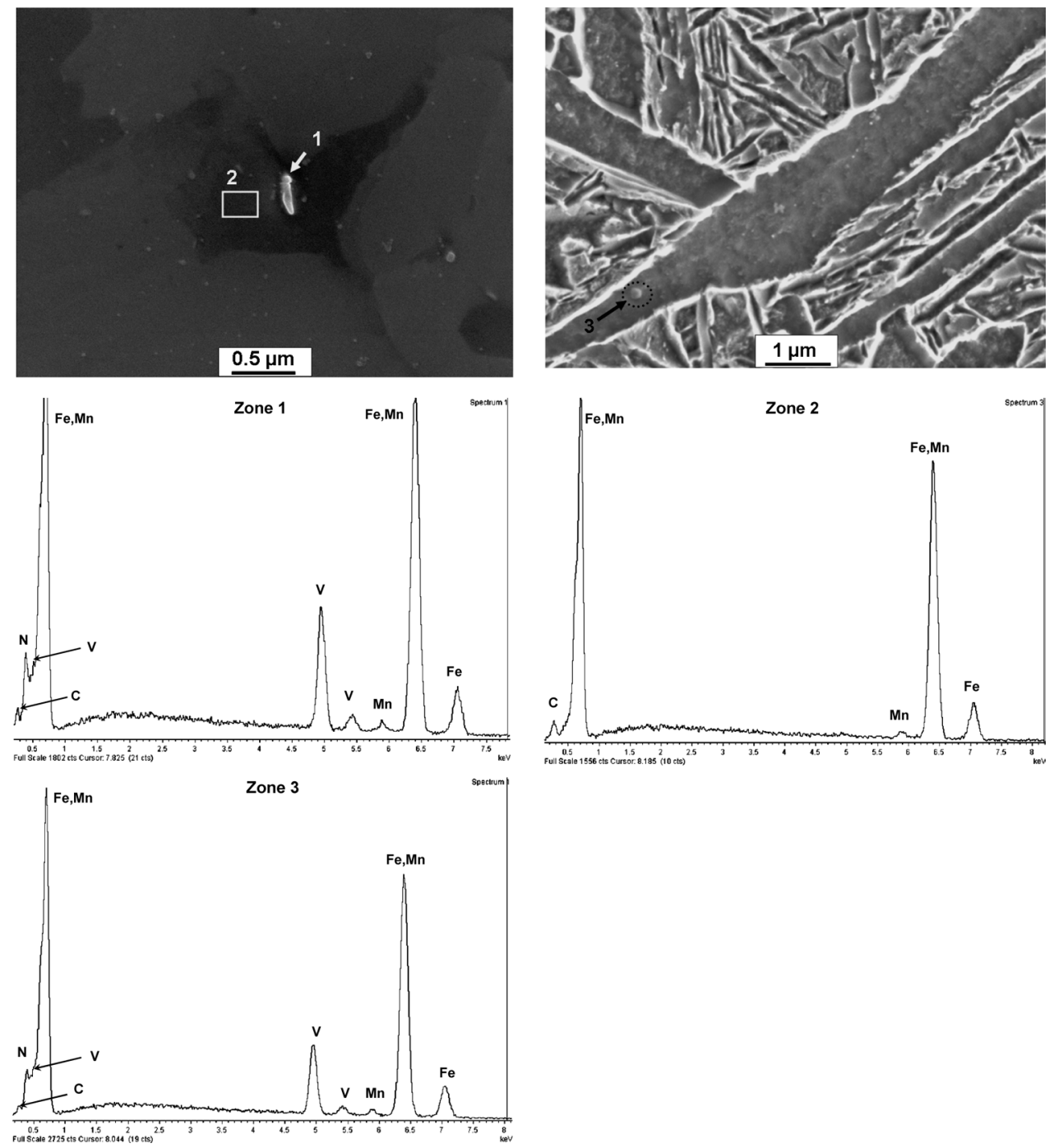

Fig. 8. Identification of $\mathrm{V}(\mathrm{C}, \mathrm{N})$ acting as nucleation sites for $\mathrm{AF}$ in $5 \mathrm{~B}$ steel. $T_{\gamma}=1125^{\circ} \mathrm{C}$, zones 1 and 2 correspond to a cooling rate of $10^{\circ} \mathrm{C} / \mathrm{s}$, zone 3 to a cooling rate of $4^{\circ} \mathrm{C} / \mathrm{s}$.

But in $5 \mathrm{~B}$ steel $\mathrm{V}(\mathrm{C}, \mathrm{N})$ precipitation has been greatly eased by the high $\mathrm{N}$ content, which increases the ratio between intragranular and grain boundary nucleation sites, ${ }^{28,29)}$ this together with the annihilation of bainite nucleation sites by the presence of proeutectoid ferrite, provide with the ideal conditions for AF formation, see Figs. 7(b) and 7(c), transcending the unfavourable situation given by a small PAGS at $T_{\gamma}=975^{\circ} \mathrm{C}$.

Whereas in $4 \mathrm{~B}$ steel heated at $975^{\circ} \mathrm{C}$ only bainite is formed, when heated at $T_{\gamma}=1125^{\circ} \mathrm{C} \mathrm{AF}$ forms but only when previously proeutectoid ferrite has appeared at low cooling rates, see e.g. Fig. 6(d). Increasing the $T_{\gamma}$ temperature lead to a higher fraction of precipitates during cooling and to a reduction of grain boundary nucleation sites, which it turns to a bigger increases of the ratio between intragranular and grain boundary nucleation sites. As the cooling rate is increased, AF is gradually replace by bainite, thus Fig. 6(e) shows a clear example of AF formation where proeutectoid ferrite was previously formed, and bainite growing from a ferrite free grain boundary, this is a clear example of the different arrangements of ferrite plates of both types of microstructures. Figure 6(f) shows the bainitic microstructure revealed after cooling at $10^{\circ} \mathrm{C} / \mathrm{s}$. Again a similar situation is given in 5B steel, i.e. the neces- sity of proeutectoid ferrite prior to AF formation, Figs. 7(d) and 7(e), and when the former does not form at higher cooling rates, bainite transformation takes place instead, as shown in Fig. 7(f). The chaotic and parallel distribution of the plates for $\mathrm{AF}$ and bainite are also clear when comparing the microstructures revealed in Figs. 7(e) and 7(f).

Finally, for $5 \mathrm{~B}$ steel cooling at $10^{\circ} \mathrm{C} / \mathrm{s}$ from $1125^{\circ} \mathrm{C}$ Fig. 8 shows an AF nucleus at an almost pure $\mathrm{V}$ nitride, zone 1. Analysis in zone 2, matrix, helps to confirm that most of the $\mathrm{C}$ detected in zone 1 corresponds to the matrix and also that the $\mathrm{Mn}$ detected in zone 1 corresponded to the matrix and not to a $\mathrm{MnS}$ associated with the $\mathrm{V}$ precipitate. Zone 3, for the same steels but a cooling rate of $4{ }^{\circ} \mathrm{C} / \mathrm{s}$, corresponds to an active $\mathrm{V}$ nitride from where an AF plate has nucleated. The fact that the precipitates are almost pure $\mathrm{V}$ nitride confirms that both precipitated in the austenitic state i.e. previous to the formation of AF.

\section{Conclusions}

In this work the influence of $\mathrm{N}$, in its combination with $\mathrm{V}$, on acicular ferrite formation has been studied. The results clearly showed that under all the austenite grain size conditions it is necessary to dishabilitate austenite grain bound- 
aries with proeutectoid ferrite so the $\mathrm{V}(\mathrm{C}, \mathrm{N})$ precipitates will become active for acicular ferrite nucleation. The low fraction of those precipitates in 4B steel, ascompared with 5B steel, explains the fact that acicular ferrite is observed in a smaller range of cooling rates or not at all. $\mathrm{N}$ is largely determining the density of $\mathrm{V}(\mathrm{C}, \mathrm{N})$ precipitation.

So, $\mathrm{N}$ in conjunction with $\mathrm{V}$ will enhance acicular ferrite formation as long as its precipitation takes place in austenite, meaning that they are almost pure nitrides, and, as it was expected, an increase of the ratio between intragranular and grain boundary sites by increasing the austenite grain size greatly eases acicular ferrite formation.

\section{Acknowledgements}

The authors would like to acknowledge the Commission of the European Communities for the financial support in the frame of the RFCS Programme for 2004 (RFS-PR03136). Also to the Spanish MCYT through the project MAT2005-24485-E. The authors are extremely grateful to J. Vara for his support in the experimental part of this work.

\section{REFERENCES}

1) S. S. Babu and H. K. D. H. Bhadeshia: Mater. Sci. Technol., 6 (1990), 1005.

2) H. K. D. H. Bhadeshia and J. W. Christian: Metall. Mater. Trans. A, 21A (1990), 767.

3) M. Strangwood: Ph. D. Thesis, University of Cambridge, Cambridge, UK, (1987).

4) H. K. D. H. Bhadeshia: Bainite in Steels, 2nd ed., ed. by The Institute of Materials, London, UK, (2001), 29.

5) S. S. Babu and H. K. D. H. Bhadeshia: Mater. Sci. Eng. A, 156 (1992), 1.

6) S. B. Singh and H. K. D. H. Bhadeshia: Mater. Sci. Technol., 12 (1996), 610 .

7) R. A. Ricks, P. R. Howell and G. S. Barriste: J. Mater. Sci., 17 (1982), 732.
8) I. Madariaga, J. L. Romero and I. Gutierrez: Metall. Mater. Trans. A, 29A (1998), 1003.

9) I. Madariaga and I. Gutierrez: Acta Mater., 47 (1999), 951.

10) J. M. Gregg and H. K. D. H. Bhadeshia: Acta Mater., 42 (1994), 3321.

11) J.-H. Shim, Y.-J. Oh, J.-Y. Suh, Y. W. Cho, J.-D. Shim and J.-S. Byun: Acta Mater., 49 (2001), 2115.

12) T. Furuhara, J. Yamaguchi, N. Sugita, N. Miyamoto and T. Maki: ISIJ Int., 43 (2003), 1630.

13) J.-S. Byun, J.-H. Shim, Y.-W. Cho and D. N. Lee: Acta Mater., 51 (2003), 1593.

14) D. Brooksbank and K. W. Andrews: J. Iron Steel Inst., 208 (1970), 495.

15) S. S. Babu: Curr. Opin. Solid State. Mater. Sci., 8 (2004), 267.

16) F. Ishikawa, T. Takahashi and T. Ochi: Metall. Mater. Trans. A, 25A (1994), 929.

17) S. Zhang, N. Hattori, M. Enomoto and T. Tarui: ISIJ Int., 36 (1996) 1301.

18) S. Zajac, S. F. Medina, V. Schwinn, A. Osta, M. De Santis and G. Herman: Final Report, EUR 22451, Luxembourg, (2007).

19) C. García de Andrés, F. G. Caballero, C. Capdevila and L. F. Álvarez: Mater. Charact., 47 (2002), 101.

20) C. Garcia de Andrés, F. G. Caballero, C. Capdevila and D. San Martin: Mater: Charact., 49 (2003) 121.

21) MTDATA National Physical Laboratory, Teddington, UK, 2003 at www.npl.co.uk/mtdata/ (access date August 4, 2008)

22) M. A. Bepari: Mater. Sci. Technol., 6 (1990), 338.

23) T. Gladman: Physical Metallurgy of Microalloyed Steels, Institute of Materials, London, UK, (1997), 218.

24) C. Garcia Mateo, B. Lopez and J. M. Rodriguez-Ibabe: Mater. Sci. Eng. A, $\mathbf{A 3 0 3}$ (2001), 216.

25) D. C. Houghton, G. C. Weatherly and J. D. Embury: Proc. Thermomechanical Processing of Microalloyed Austeniteed, ed. by A. J. De Ardo, Metallurgical Society of AIME, New York, (1982), 267.

26) S. Gunduz and R. C. Cochrane: Mater. Des., 26 (2005), 486.

27) R. Lagneborg, T. Siwecki, S. Zajac and B. Hutchinson: Scand. J. Metall., 28 (1999), 186.

28) C. Capdevila, F. G. Caballero, C. García-Mateo and C. García de Andrés: Mater: Trans., 45, (2004), 2678.

29) C. Capdevila, F. G. Caballero and C. García de Andrés: Mater. Sci. Technol., 19 (2003), 195. 